\title{
LAS EXPRESIONES ARTÍSTICAS DE LAS VÍCTIMAS COMO MECANISMO DE REPARACIÓN TRANSFORMADORA EN COLOMBIA. EL CASO DE “LAS TEJEDORAS DE MAMPUJÁN”
}

\author{
The artistic expressions of the victims as way of transformer reparation in Colombia. \\ The "Tejedoras de Mampujan" case
}

Alejandro SANABRIA RODELO*

Sumario:

1. Introducción 2. La relación de las expresiones artísticas como forma de reparación simbólica de las victimas dentro de la reparación integral 3. Las expresiones artísticas de las víctimas como oportunidad para construir mecanismos concretos de reparaciones transformadoras 4. Conclusiones.

Resumen. Esta disertación en primer lugar pretende contextualizar el caso de las "Tejedoras de Mampuján" dentro del conflicto armado en Colombia, específicamente la violencia de los Montes de María, un territorio que ha sufrido por décadas la desprotección estatal. En segundo lugar identificar la importancia del arte como medio de expresión de las víctimas y como forma de reparación simbólica dentro de la reparación integral. Finalmente dilucidar la oportunidad para que las expresiones artísticas de las víctimas sean adecuadas para formular mecanismos concretos y medios alternativos de solución del conflicto además de formular garantías de no repetición que lleven a una reparación restauradora, esencial para la participación del Estado y de la sociedad civil, en procesos democráticos.

Palabras clave: Reparación, desplazados, democracia, conflicto armado, artes, derechos humanos.

\begin{abstract}
This dissertation, in first place pretends to show the role and context of the "Tejedoras de Mampuján" in the Colombian internal war, specifically analyzing the violence in the region called: "los Monjes de María" a territory that had suffered for years the statal forgetfulness. In second place, it purports to find the importance of the art as way of expression of the victims and as a mean of symbolic reparation in the development of integral reparation. Finally, it exhibits that giving the opportunity for the artistic expressions of the victims will be an appropriate form for have concretes and alternative ways of solution of conflicts, provides non repetition safeguards for the warlike acts, in the road of the a restorative reparation.
\end{abstract}

Keywords. Reparation, displaced, democracy, armed conflicto, art, human rights.

* Estudiante e investigador de la Facultad de Derecho de La Universidad Externado de Colombia. Mail: alejandro.sanabri@est.uexternadi.edu.co; alejandro-req@hotmail.com 


\section{Introducción}

El conflicto armado en Colombia ha tenido como en muchos países de América Latina altos grados de complejidad. Han sido 52 años de guerra que han dejado 8.230.860 víctimas registradas, estas soportaron en su mayoría hechos victimizantes como asesinatos, masacres, desaparición forzada y desplazamiento forzado ${ }^{1}$

Además, la desigualdad en Colombia es una condición estructural, contando con 53,5 puntos en el coeficiente de Gini y un índice de pobreza de $27,8 \%{ }^{2}$. Se puede decir que existe una violación masiva a los Derechos Humanos consecuencia de un evidente abandono del estado y la carencia de prestaciones básicas para mantener una vida digna en gran parte del territorio.

A su vez, estas condiciones de desigualdad social e inexistencia institucional del Estado han permitido que la condición de víctima adquiera un carácter permanente, debido a que, lastimosamente, los más afectados por la violencia han sido en su gran mayoría las personas a las que por sus condiciones socioeconómicas les es más difícil superar hechos victimizantes en el contexto de la guerra ${ }^{3}$.

Personas que viven o vivieron, al momento de las vulneraciones a sus derechos, en zonas rurales donde el acceso de las fuerzas militares, y de los servicios públicos esenciales son altamente limitados, tanto por su complejidad geográfica como por la permanente presencia de grupos armados al margen de la ley en esas regiones ${ }^{4}$.

Por ejemplo, en Colombia, solo en los departamentos de Sucre y Bolívar se han registrado un total de 585.218 víctimas, de las cuales solo $11.457^{5}$ han conseguido una sentencia en un proceso judicial que reconozca las violaciones a sus derechos. Por otro lado la falta de reconocimiento de las personas de las regiones más vulnerables del país, no solo contribuyó en la ocurrencia de su victimización, sino que además, aún hoy favorecen la invisibilidad de estas. En palabras de la Comisión Nacional de Memoria Histórica de Colombia en el informe de memoria histórica Basta ya:

El daño que se le hace a la víctima se le inflige a toda la humanidad. No obstante, aunque el conflicto armado en el país ha cobrado millares de vidas, muchos conciudadanos, lo sienten un asunto ajeno a su entorno y a sus intereses. Las víctimas y sobrevivientes sufren la violencia en medio de profundas y dolorosas soledades. Esto se explica en parte porque la guerra se hizo

\footnotetext{
${ }^{1}$ Cifras tomadas del Registro único de víctimas (RUV) Estos datos son tomados desde un punto de vista territorial y expresan las víctimas registradas en todo el territorio nacional. Las cifras concretas por violaciones a derechos humanos son: desplazamiento, 6.977.713; desaparición forzada, 164.851; domicidio, 981.509. entre otros.

2 Departamento Administrativo Nacional de Estadística (DANE, 2016), Pobreza monetaria y multidimensional en Colombia 2015, [en línea], disponible en: https://www.dane.gov.co/files/investigaciones/condiciones_vida/pobreza/bol_pobreza_15_.pdf(consultado el 24 de septiembre de 2017).

3 Umaña, Eduardo, Falls, et al. (1962), La Violencia en Colombia. Bogotá: Tercer Mundo.

4 Centro Nacional de Memoria Histórica (2013), Informe: ¡Basta ya! Colombia: Memorias de guerra y dignidad. [en línea], disponible en: http://www.centrodememoriahistorica.gov.co/descargas/informes2o13/bastaYa/ basta-ya-memorias-guerra-dignidad-new-9-agosto.pdf

5 Estas cifras son oficiales, fueron tomadas del Registro Único de Víctimas. Institución creada por la ley 1448 de 2011 como una propuesta para el reconocimiento de las víctimas del conflicto armado en el país. Sin embargo es un estimado que se hace con base en diferentes mecanismos de recopilación de datos, que pueden tener insuficiencia en algunos casos por las mismas complejidades del conflicto.
} 
cotidiana, porque transcurre en la ruralidad del país, y porque la mayoría de quien sufren son personas anónimas ${ }^{6}$.

De tal manera gran parte de las víctimas han sido damnificadas: por la ineficacia del Estado para cumplir con su obligación de garantizar sus derechos, por las violaciones a derechos humanos por parte de grupos armados y por la carencia de solidaridad y reconocimiento de la historia de las víctimas por parte de la sociedad civil.

Está realidad desembocó en la adaptación de medidas de reparación, que mediante la ley 1448 de 2011 (Ley de víctimas y restitución de tierras) ${ }^{7}$, incorporó en el ordenamiento jurídico colombiano todo un sistema de reparación integral basado en los Principios para la protección y la promoción de los derechos humanos para la lucha de la impunidad dictados por la Organización de Naciones Unidas (ONU) en el año 1997 y, en la jurisprudencia de la Corte Interamericana de Derechos Humanos ${ }^{8}$.

En estos instrumentos la reparación integral tiene cinco componentes que se complementan entre sí, y que son: restitución, indemnización, rehabilitación, medidas de satisfacción y garantías de no repetición. Estos componentes están encaminados a la restitución de los derechos de las víctimas, limitándose a intentar retrotraer sus condiciones a un estado anterior a la vulneración de sus derechos ${ }^{9}$. Sin embargo, como se expuso anteriormente, muchas de las personas que fueron víctimas del conflicto armado vivían en situaciones de vida indignas antes de las hostilidades y estas condiciones de desigualdad e indignidad contribuyeron en gran medida a las atrocidades en sus regiones y a la escasez de mecanismos legítimos para proteger sus derechos.

De esta manera la reparación integral que proponen los diferentes instrumentos jurídicos se hace insuficiente para la satisfacción de los derechos de las víctimas, no solo en el contexto del conflicto armado sino además en el curso cotidiano de sus vidas. Frente a esta limitación del concepto de reparación integral ${ }^{10}$, propone que el Estado mediante la reparación integral debe buscar reparaciones transformadoras ${ }^{11}$, que contribuyan no solamente a la superación de las violaciones de los derechos de las víctimas, sino que además contribuyan en transformar a la

6 Centro Nacional de Memoria Histórica (2013), Informe, ¡Basta ya! Colombia: Memorias de guerra y dignidad, [en línea], disponible en: http://www.centrodememoriahistorica.gov.co/descargas/informes2013/bastaYa/ basta-ya-memorias-guerra-dignidad-new-9-agosto.pdf. p. 16

7 La ley de víctimas fue la respuesta del gobierno a la necesidad de participación de las víctimas y su reparación en el marco de la justicia transicional a partir del proceso de paz con las Autodefensas Unidas de Colombia (AUC) en el año 2005, está ley contempla laos diferentes componentes de la reparación integral, establecidos en los principios de la ONU para la protección y la promoción de los derechos humanos y la lucha contra la impunidad del año 1997, y el procedimiento de restitución de tierra ante los despojos ocasionado por diferentes grupos al margen de la ley.

8 Este concepto es reconocido por la Convención Americana de Derechos Humanos y por la Corte InteRAMERICANA desde su primer caso contencioso en 1986, Velásquez RodríGuez Vs. Honduras.

9 Uprimny, Rodrigo \& SAFfón, Maria Paula (2009), Reparaciones transformadoras, justicia distributiva y profundización democrática. Reparar en Colombia: los dilemas en contextos de conflicto, pobreza y exclusión. Dejusticia \& ICTJ (pp. 31-71).

10 Ídem.

${ }^{11}$ Está advertencia es propuesta en la publicación Reparar en Colombia. Los dilemas en contextos de conflicto, pobreza y exclusión, Catalina Díaz Gómez et al. (eds.), concretamente de la Parte I, capítulo Reparaciones transformadoras, justicia distributiva y profundización democrática. 
sociedad para que se solucionen las condiciones de desigualdad que favorecieron la causas por las que surgió el conflicto armado en estas regiones que ya eran vulnerables con anterioridad.

En el marco de la reparación integral, y buscando iniciativas que busquen reparar a las víctimas no solo desde un enfoque restitutivo sino además desde los enfoques transformador y dignificador, encontramos diferentes experiencias que desde el arte contribuyen de gran manera tanto a devolverle el conflicto a las víctimas ${ }^{12}$.Y sobre todo a otorgarles reconocimiento real a las personas de regiones vulnerables, que conocieron las atrocidades de la guerra, aportando a la superación de las condiciones de desigualdad social que facilitaron estás hostilidades. Uno de los casos más importantes frente a estas expresiones artísticas, son las Tejedoras de Mampujan.

Mampujan está ubicado en una región de Colombia que se le conoce como los Montes de María $a^{13}$ una región selvática, en el valle de pequeños cerros cerca a la costa Caribe y rica en recursos naturales y diferentes clases de cultivos como arroz y tabaco. Son una región del país que ha resaltado por la inexistencia del Estado en materia de servicios públicos y por la permanente presencia de grupos armados. En esta región, el conflicto dejó 56 masacres, miles de personas desplazadas, y una herida de violencia que sirve de testigo de la barbarie de la guerra ${ }^{14}$.

La masacre de Mampuján ocurrida entre el 10 y 11 de marzo del año 2000 dejó un saldo de 245 familias desplazadas y 12 personas masacradas con vileza. Frente a esto, diferentes sectores de la sociedad civil han colaborado para que después de muchos años se construyera Rosas de Mampuján o como lo llaman sus pobladores Mampuján la nueva.

En esta nueva ubicación (también situada en los Montes de María) las 245 familias continuaron con su vida, pero con la carga constante de superar lo acontecido. En medio de esa confrontación con la violencia y las condiciones precarias de subsistencia en su nuevo territorio. Algunas mujeres mediante el acompañamiento de algunas organizaciones y colaboradores, empezaron a catalizar el impacto de la guerra en sus vidas y su identidad en Tejidos, que han servido como un mecanismo para superar el trauma ocurrido y superar su situación victimizante ${ }^{15}$.

Este proyecto ha contribuido de manera muy positiva a la satisfacción de los derechos de las víctimas, dándoles dignidad y aportando significativamente a su reparación, sin embargo el Estado nunca participó ni apoyo el proyecto de las Tejedoras; de hecho, solo hasta el 2014 empezaron a ejecutar las medidas de reparación integral consagradas en la ley de víctimas ${ }^{16}$.

Con el apoyo del Estado en los proyectos de expresión artística de las comunidades víctimas, se abriría una oportunidad para que sus esfuerzos tengan resonancia en todo el país, aportando al reconocimiento de su historia y generando visibilidad ante la sociedad civil, y así generar garantías que aseguren la existencia de recursos efectivos y legítimos para la exigencia en la

\footnotetext{
${ }^{12}$ Christie, Nils (1984), The limits of pain. Oslo: Universitetsforlaget.

${ }^{13}$ Los Montes de María (conocidos también como Serranía de San Jacinto) es una subregión del Caribe colombiano de $2.677 \mathrm{~km} 2$, ubicada entre los departamentos de Sucre y Bolívar.

${ }^{14}$ Verdad Abierta. (2012) ¿Verdad a medias, reparación inconclusa?, [en línea], disponible en: http://www.verdadabierta.com/component/content/article/45-reparaciones-a-victimas/3924-mampujan-iverdad-a-medias-reparacion-inconclusa. (consultada el 24 de septiembre de 2017).

${ }^{15}$ Centro Nacional de Memoria Histórica (2012), Mampuján. Crónica de un desplazamiento. [En línea], disponible en: http://www.banrepcultural.org/blaavirtual/memoria-historica/documentales (consultado 24 de septiembre de 2017).

16 Tribunal Superior del Distrito de Bogotá. Col. Sala de justicia y paz, 29 de junio de 2010. CP. ULDI Teresa Jiménez López. Postulados: Edward Cobos Téllez y Uber Enrique Banquéz M.
} 
protección de sus derechos, tanto por su condición de víctimas como por su condición de ciudadanos.

Con base en los anteriores elementos y tomando el caso de las Tejedoras de Mampuján como ejemplo, demostraremos como las expresiones artísticas de las víctimas son una oportunidad para concretar reparaciones transformadoras que impacten directamente sobre la desigualdad social de las regiones afectadas por el conflicto.

De esta manera, en primer lugar, mostraremos la relación de las expresiones artísticas de las víctimas con la reparación integral y en segundo lugar explicaremos porque las expresiones artísticas de las víctimas como reparación son una oportunidad para construir mecanismos concretos de reparación transformadora.

\section{La relación de las expresiones artísticas como forma de reparación simbólica de las victimas dentro de la reparación integral}

Para hablar del concepto de reparación integral, debemos partir de la existencia cierta de una violación a los derechos humanos de una persona o grupo de personas ${ }^{17}$. Este es el caso de la población de Mampujan que no solo fue forzada a salir de sus territorios, sino como consecuencia de este desplazamiento, se vieron obligadas por un largo tiempo a vivir en condiciones precarias, que atentaban su dignidad y calidad de vida.

Como se enunció anteriormente la reparación integral comprende cinco elementos, que tienen como fin el resarcimiento de las víctimas desde las diferentes esferas que la componen como persona, sujeto de derecho y sujeto social. La primera de ellas es la restitución que tiene como finalidad devolver a la víctima a la situación en la que se encontraba antes del hecho victimizante, lo que implica la reposición de sus bienes patrimoniales y el restablecimiento de sus derechos. En segundo lugar, tenemos la indemnización que busca reparar a las víctimas materialmente por medio de una compensación patrimonial. En tercer lugar, los mecanismos de rehabilitación; atención médica, psicológica, servicios jurídicos y sociales que requiera la víctima. En cuarto lugar, las medidas de satisfacción que buscan reconocer públicamente el daño sufrido por estas con el fin de dignificarlas y en último lugar, las garantías de no repetición que se diferencian de las mencionadas anteriormente y buscan evitar que los sucesos ya acaecidos se repitan a través de diferentes medios ${ }^{18}$.

Dentro de estos elementos, que tienen como fin asegurar la reparación integral y lograr aportar a la justicia mediante la justicia restaurativa, podemos dilucidar la reparación simbólica, como un mecanismo que cumple un papel fundamental e indispensable para garantizar los supuestos de satisfacción y garantías de no repetición.

En Colombia la ley de víctimas ha definido reparación simbólica como:

Artículo 141. Reparación Simbólica. Se entiende por reparación simbólica toda prestación realizada a favor de las víctimas o de la comunidad en general que tienda a asegurar la preservación de la memoria histórica, la no repetición de los hechos victimizantes, la aceptación pública de

\footnotetext{
${ }_{17}$ Rousset, Andrés (2011), El concepto de reparación integral en la jurisprudencia de la Corte Interamericana de Derechos Humanos Revista Internacional de Derechos Humanos, N 59 o 1.

${ }^{18}$ Uprimny, Catalina. (2014), Memoria y reparación simbólica: experiencia con algunas iniciativas no oficiales de memoria en Colombia Revista Arte y Derecho n. 11. p. 78.
} 
los hechos, la solicitud de perdón público y el restablecimiento de la dignidad de la dignidad de las víctimas ${ }^{19}$.

La reparación simbólica busca llevar a una situación nueva, a partir del reconocimiento de lo ocurrido y por medio de la simbolización, el reconocimiento de los hechos, el perdón tanto individual como colectivo y la construcción de memoria histórica. Este tipo de reparación tiene dos finalidades: La primera es garantizar la satisfacción de las víctimas a través de la dignificación de sus derechos. Esta garantía se ve plasmada desde tres postulados esenciales: la dignificación de la víctima, el derecho a la verdad y la construcción de la memoria histórica. Estos supuestos van encaminados a la atención de las víctimas desde una esfera individual. Y como segunda finalidad tenemos las garantías de no repetición que van encaminadas a la construcción de la memoria colectiva, además de la contribución del desarrollo de una identidad común que pretende asegurar la no repetición de los hechos acontecidos ${ }^{20}$.

Dentro de la reparación simbólica las expresiones artísticas tienen un papel esencial, ya que, se convierten en el medio de representación simbólica más importante para manifestar el dolor y convertir los hechos del pasado en una narrativa del presente, dejando de ser un mero ejercicio estético. Estas pueden ser representadas desde cualquier manifestación artística, como expresiones musicales, pintura, teatro o un tejido pero en cualquier caso logran crear un símbolo tanto de representación individual como colectiva ${ }^{21}$.

En consecuencia, la reparación simbólica, podemos identificarla con gran claridad en el caso de Mampujan, ya que las víctimas desarrollaron estos telares como forma de superación de sus hechos victimizantes, como mecanismo de perdón y, como reconocimiento de su dignidad. Gracias a esto se logró construir un proceso de memoria, haciendo de sus telares un símbolo que ahora está inmerso en la memoria del país; creando relaciones catárticas en los más profundo de las zonas más inaccesibles y donde hay una clara desprotección por parte del Estado.

Este importante proyecto lo han logrado desde un trabajo conjunto con otras organizaciones y diferentes sectores de la sociedad civil, ya que la incidencia del Estado en este caso fue mínima por no decir prácticamente nula. Aquí los telares no solo son una expresión artística o unos presupuestos más de la reparación simbólica, sino que también son un acto político, símbolo de lucha y un referente directo de la historia en Mampujan ${ }^{22}$.

Es importante reevaluar el papel del Estado y de los victimarios en éste proceso, ya que no se podría hablar de que hubo reparación de ningún tipo, si los proyectos fueron desarrollados exclusivamente por las víctimas. Si lo aceptaremos estaríamos trasladando la carga de la reparación, olvidándonos de la responsabilidad de los victimarios y del Estado en la superación de los hechos victimizantes, y la satisfacción de los derechos.

Aunque se entiende la complejidad e imposibilidad del Estado de abarcar la satisfacción de los derechos a la verdad y reparación de las víctimas está en la obligación legal. Así es como en la ley de víctimas en su artículo 14 establece:

\footnotetext{
${ }^{19}$ Ley 1448 de 2011 , ley de víctimas y restitución de tierras.

${ }^{20}$ Sierra, Yolanda (2014), Relaciones entre el arte y los derechos humanos. Revista Derecho del Estado n. 32, pp. 77-100.

${ }^{21}$ Roca, José y Suarez, Sylvia (2012), Arte en Colombia 1992-2012. Barcelona: Luwerg y Transpolítico.

22 Figueroa, P y Moreno, E. (2014), Revista de Arte y Derecho. Reparacion Simbolica: procesos artísticos y pedagógicos en escenarios sociales.
} 
La superación de vulnerabilidad manifiesta de las víctimas implica la realización de una serie de acciones que comprende:

El deber del Estado de implementar las medidas de atención, asistencia y reparación a las víctimas.

El deber de solidaridad y respeto de la sociedad civil y el sector privado con las víctimas, y el apoyo a las autoridades en los procesos de reparación; y La participación activa de las vícti$\mathrm{mas}^{23}$.

Por lo tanto como el Estado está en la obligación de participar en la reparación de la víctima de forma complementaria y conforme al principio de solidaridad.

Por otro lado la Constitución Nacional de Colombia, establece como fin esencial del Estado: servir a la comunidad, promover la prosperidad general y garantizar la efectividad de los principios, derechos y deberes consagrados en la Constitución ${ }^{24}$. Es por esto que se debe evaluar y darle un tratamiento diferenciado en cada caso donde haya existido una vulneración a derechos humanos, ya que los hechos victimizantes, y el proceso de trámite de dolor en cada caso es diferente y también responde a una coyuntura y contexto específico. Igualmente el Estado tiene que involucrarse en todo el proceso de expresión de las víctimas para lograr reparar simbólicamente, a través de un equipo capacitado que logre ver cuáles son las necesidades de estas para así poderles brindar la ayuda y el respaldo institucional que estas requieran ${ }^{25}$.

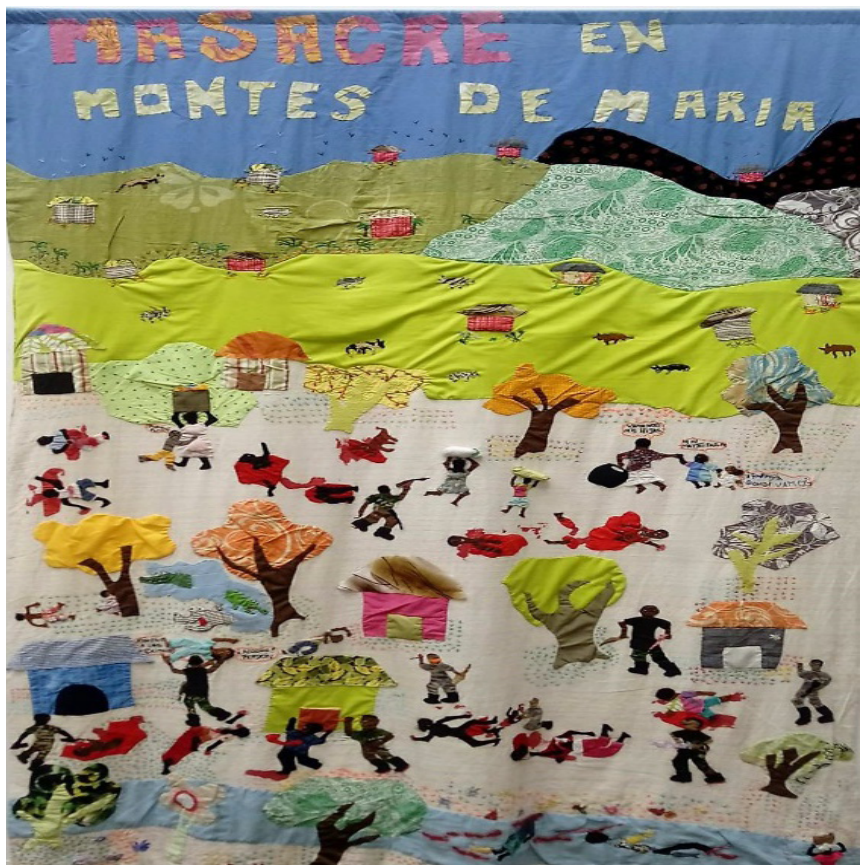

Obra: Masacre de Montes de María Año: 2009

Autor: Tejedoras de Mampuján

Bordado en tela $(194 \times 121 \mathrm{~cm})$

\footnotetext{
${ }^{23}$ El artículo 14 de la ley 1448 de 2011, ley de víctimas y restitución de tierras ratifica el deber de solidaridad del Estado con las víctimas y es fundamento para las indemnizaciones administrativas que contempla la ley.

${ }^{24}$ Constitución Política NACiOnal de Colombia artículo 2.

${ }^{25}$ Ibídem, p. 7 .
} 


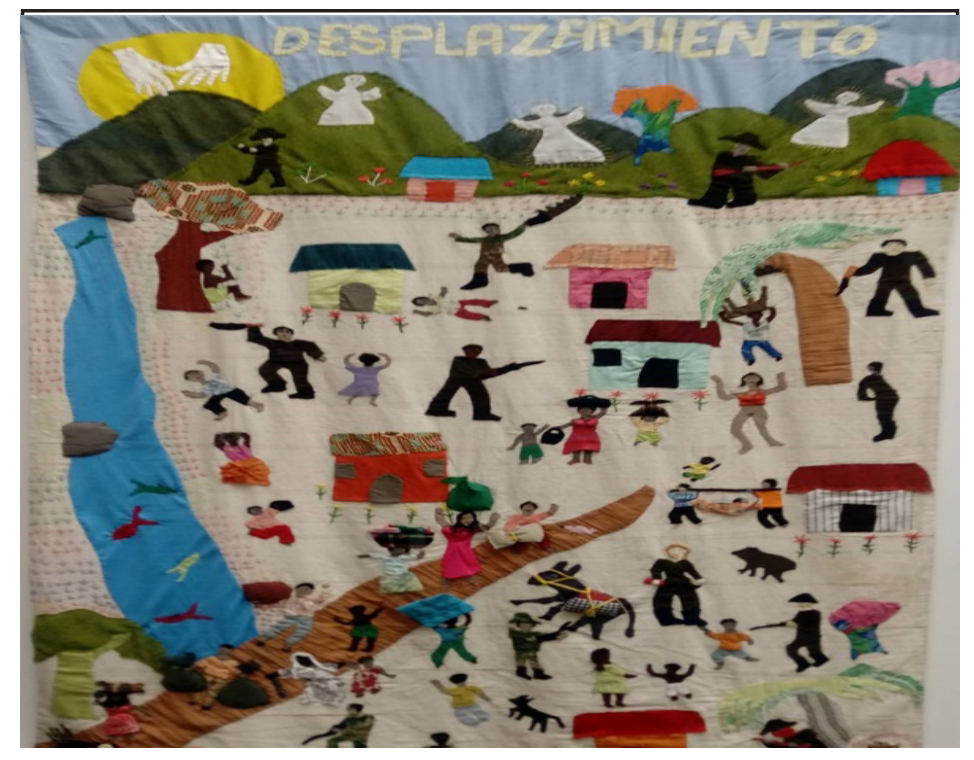

Obra: Desplazamiento Año: 2009

Autor: Tejedoras de Mampuján

Bordado en tela $(194 \times 121 \mathrm{~cm})$

\section{Las expresiones artísticas de las víctimas como oportunidad para construir mecanismos concretos de reparaciones transformadoras}

Según los criterios establecidos por la Corte Constitucional ${ }^{26}$ el deber de reparación de las víctimas corresponde en primera medida a los victimarios directos, entregando a las autoridades los bienes que tengan un objeto tanto lícito como ilícito y, lo que haya pertenecido al grupo al margen de la ley al cual pertenece el victimario. En segundo lugar y de forma complementaria corresponde al Estado.

Por lo que las reparaciones a las que se refiere la Corte tienen un ánimo restitutorio económico e indemnizatorio, que no excluye a las víctimas a integrarse a la ejecución de su propia reparación en lo que concierne a medidas de satisfacción y garantías de no repetición.

Históricamente el arte ha estado en manos de muy pocas personas en la sociedad, casi siempre en manos de las personas de clases socioeconómicas altas, lo que explica porque el arte y lo que se considera artístico ha sido el monopolio incuestionable de formas de expresión creadas desde las ciudades. Esto conllevó a que se deje en la sombra las expresiones artísticas que desde los barrios o desde las regiones más recónditas han ido surgiendo; obras que también son parte de nuestra cultura y construyen nuestra identidad ${ }^{27}$.

De esta manera, el reconocimiento de las expresiones artísticas de las víctimas, como los Tejidos de las víctimas de Mampujan son esenciales para romper los paradigmas de desigualdad social y de carencia efectiva de oportunidades de todo tipo, en las sociedades históricamente vulnerables. El arte se convierte en una oportunidad clara de concretar reparaciones transfor-

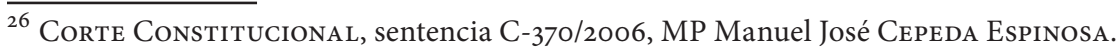

27 Castillo, Raúl; Rafael et al. (2012), Arte para la inclusión y la transformación social. Bilbao: Equipo del Observatorio del Tercer Sector de Bizkaia.
} 
madoras y democráticas que aspiren a la inclusión social y a la satisfacción de derechos de las víctimas.

Sin embargo esto no quiere decir que las víctimas no necesiten el resto de medidas y componentes de reparación integral, por lo que no se podría decir que estos entran en tensión con la reparación transformadora. De hecho para hacer de la transición de las hostilidades una transformación democrática que reduzca la desigualdad, hay que ejecutar las medidas de reparación integral con un enfoque transformador, dignificador y democrático.

\subsection{Las expresiones artísticas de las víctimas como oportunidad para solucionar las causas del conflicto y formular garantías de no repetición}

Los grupos armados que perpetraron la masacre de Mampuján, desplazaron a todo el pueblo, fueron 245 familias que fueron obligadas a irse por la atroz voluntad del grupo paramilitar.

Los Tejidos se volvieron para estas personas no solo un mecanismo para confrontar el dolor mediante el arte-terapia, sino además se convirtieron, en una forma de construir identidad en el desplazamiento y mantener la cultura en su nuevo territorio, pero sobre todo, sirvió para que miles de personas conozcan su historia.

Así vemos como muchas de estas, son medidas simbólicas que trascienden de las víctimas y se dirigen hacia la sociedad, para que esta reconozca sus vidas y evite la repetición de las hostilidades ${ }^{28}$.

Por lo que ante la tardía ejecución de las normas de reparación a estas víctimas, ellas mismas pudieron salir de su hecho victimizante a través del arte, satisfaciendo en gran medidas la rehabilitación, y contribuyendo a las medidas de satisfacción de las que era responsable el Estado. En palabras de una de las tejedoras:

En la medida de que empezábamos a cocer y hablar del tema, descubríamos que teníamos muchas heridas en ese momento cuando ya empezábamos a trabajar, nos dimos cuenta que era bueno, iba quedando una memoria allí en esa tela e iba quedando como bonito, y en la medida que íbamos sacando las cosas, íbamos recibiendo una sanidad, poco a poco y cuando quisimos terminar el tapiz, nos dimos cuenta que ya nos reíamos, cuando nos tocaba recordar una historia de alguno, nos daba mucho sentimiento pero al final nos daba hasta risa $[\ldots]^{29}$.

Se observa que en este caso las expresiones artísticas fueron el mecanismo para que las víctimas pudieran superar las violaciones a sus derechos, al menos en los campos que no tienen que ver con las necesidades económicas tradicionales de la región.

La experiencia de los Tejidos de Mampuján tuvo un gran impacto en la sociedad, que reconoció la historia de vida y el trabajo de las familias desplazadas de Mampuján, las cuales recibieron varios reconocimientos por sus tejidos. Diferentes universidades, organizaciones e instituciones $^{30}$, reconocieron los tejidos como parte de la memoria histórica nacional, y permitieron que

\footnotetext{
${ }^{28}$ PAtiño, Andrés (2010), "Las reparaciones simbólicas en escenarios de justicia transicional”, Revista Latinoamericana de Derechos Humanos Vol. 21 (2): 60.

29 Testimonio de una de las tejedoras de Mampuján documentado por el Centro Nacional de Memoria Histórica. Ibídem.

${ }^{30}$ Por citar unos cuantos ejemplos: reconocimientos al premio nacional de paz en el año 2015; la Universidad Externado expone actualmente una exhibición artística en su campus sobre los Tejidos. También en el Museo Nacional ubicado en la ciudad capital de Bogotá se encuentra un tejido que estará exhibido por 20 años.
} 
se dejara de ocultar a estas familias detrás de cifras, para exponer y entender la historia de sus vidas y la violación a sus derechos.

Los tejidos abrieron la puerta para que la sociedad se enterara no solo de los hechos victimizantes, sino también del abandono estatal que sufría la población al momento de las atrocidades, esto es un claro ejemplo de como las expresiones artísticas de las víctimas están encaminadas, no solo a la reparación simbólica sino además a denunciar y explicar las causas que permitieron la violencia en las distintas regiones.

Diferentes autores conciben que las reparaciones simbólicas deben buscar dignificar y reconocer a las víctimas, recordar la verdad de los hechos victimizantes y exponer la responsabilidad por parte de los victimarios ${ }^{31}$.

Expresiones artísticas como las Mampuján pueden generar el impacto suficiente para sensibilizar a la sociedad y a los operadores jurídicos, para otorgar oportunidades concretas de reparaciones transformadoras. Así las expresiones artísticas como lo mencionamos anteriormente no solo serán medidas de reparación simbólica, sino que además, si se ejecutan bien pueden contribuir a transformar de manera democrática a la sociedad, y crear no solo garantía de no repetición de las hostilidades si no garantías para la protección integral de los derechos.

De esta manera si se busca una transformación democrática que este encaminada, cumplimiento de deber constitucional del Estado de garantizar los derechos personalísimos de los ciudadanos que viven en situaciones de vulnerabilidad, se tendrá que interpretar el concepto de reparación integral desde un punto de vista transformativo, al respecto Uprimny y Saffón establecieron:

Por cuanto el enfoque o la vocación transformadora de las reparaciones constituye una forma alternativa de concebirlas, según la cual su alcance no debe limitarse a la violación concreta y al daño causado por ella, sino que debe extenderse a las condiciones de exclusión que la hicieron posible, y porque el propósito de las mismas debe consistir tanto en reparar aquel daño como en transformar democráticamente estas condiciones ${ }^{32}$.

Está reparación transformadora puede concretarse, a través de políticas públicas para el reconocimiento de la historia de vida de las víctimas, no solo a partir de cifras, sino del testimonio que cuenten las expresiones artísticas.

Esto puede incentivar la inversión económica en regiones que anteriormente fueron vulnerables, además de hacer presión política a las diferentes instituciones estatales para que hagan un acompañamiento constante en estas regiones, garantizándoles el cubrimiento de servicios públicos básicos, como el agua potable, y la energía, e instalar puestos de policía y ejército que garanticen su seguridad.

Si bien la reparación simbólica a partir de estas expresiones artísticas, por sí solas no garantizaran la existencia del Estado y la superación de todas sus necesidades, si garantiza que nunca más estás personas vayan a ser olvidadas por el país, esto desembocará en disminuir la desigualdad, a partir de la generación de empleo y educación en la región a través de la inte-

\footnotetext{
${ }^{31}$ Ibídem, p. 13 .

${ }^{32}$ Ibídem, p. 42. 
gración de diferente sectores, como el ministerio público, el gobierno nacional y la inversión de particulares en la zona.

Por ejemplo, desde que la noticias de sus Tejidos han sido divulgados por medios de comunicación, el interés de la sociedad civil y del Estado ha incrementado, es así como desde esta divulgación se han hecho documentales, se han escrito libros, y han involucrado a las tejedoras en diferentes eventos para que cuenten su historia, lo que ha hecho que puedan exponer sus tejidos y tengan nuevas oportunidades de empleo.

\subsection{El rol del Estado y de la sociedad civil en las reparaciones transformadoras desde las expresiones artísticas de las víctimas}

Como lo explicamos anteriormente, sería contradictorio decir hubo reparación si está vino exclusivamente de las víctimas; ya que estaríamos imponiéndoles una carga que no les corresponde olvidándonos de la responsabilidad de los victimarios y del Estado para que la reparación se concrete. Esto no quiere decir que las víctimas no deban participar en su propia reparación.

La guerra descompone el tejido social contundentemente, la falta de justicia o de reparación podría repercutir en la repetición de las hostilidades o en la venganza de las víctimas. Por esta razón y con el ánimo de avanzar hacía reconciliación es que se deben incluir a las víctimas directamente en los procesos ya que en estos normalmente la víctima no tiene un rol relevante sino que interponen al victimario ya su responsabilidad penal en el centro de los procesos, robándole el conflicto a las partes ${ }^{33}$.

Para que esto suceda y las víctimas no tengan la sensación de impunidad, se deben buscar formas en las que se integren a la víctima, al victimario y al Estado para hallar medidas concretas que se ejecuten, en la reparación integral de las víctimas, haciendo énfasis en las garantía de no repetición y la transformación democrática, que solucione directamente las causas del conflicto.

El Estado se debe involucrar directamente, incentivando las expresiones artísticas que desde las víctimas se hacen y pasar a una transformación democrática. Estás medidas pueden ser: realizar una política pública para la divulgación de la cultura de las víctimas y de las personas que viven en las regiones más marginadas del país, integrar a las diferentes instituciones públicas de la sociedad para que presten atención a las historias y denuncias que mediante el arte se hacen y solucionar progresivamente obstáculos sociales que generen desigualdad, confrontar a las víctimas y a los victimarios y hacer que los victimarios conozcan de las expresiones artísticas de las víctimas para que se recomponga el tejido social, entre otras.

Los victimarios deben reconocer, los hechos que expresan el arte de las víctimas, y ejecutar las medidas de satisfacción necesarias para la reparación no pecuniaria de las víctimas, lo que no los exime de cumplir en la medida de las posibilidades con el resto de los componentes de la reparación integral.

\section{Conclusiones}

Colombia es un país de matices, con un conflicto armado largo y complejo, donde los deseos de paz son tal vez nuestro único referente de identidad. Un país que camina constantemente hacía

${ }^{33}$ Ibidem, p. 14 . 
la superación de la violencia y que la desigualdad es el contenido de una denuncia cotidiana, a la que nunca se acostumbra.

La reparación integral supone grandes retos para la sociedad, retos que pueden ser la oportunidad para construir un país más justo y garantista de los derechos, a su vez supone retos para el Estado que debe involucrar a las víctimas en la solución de los conflictos y la reconciliación de las diferentes esferas de poder. Esta reparación se debe ver desde un punto de vista transformativo, analizando las causas históricas del conflicto y solucionándolas, para no solo visibilizar las atrocidades propias de la guerra sino dejar presente un mensaje preventivo de las causas de la misma.

Los Tejidos de Mampuján han sido un ejemplo de superación para toda la nación, un ejemplo que demuestra como el arte puede ser un instrumento positivo de cambio, que contribuye a la memoria y a la transformación. Este instrumento hace visible a las personas que durante años fueron invisibles, hace que reconozcamos el abandono estatal, la complejidad del conflicto armado y nuestro deber de detenerlo para siempre.

El Estado tiene la oportunidad, mediante las expresiones de las propias víctimas de reivindicar sus derechos, y de garantizar su dignidad con acciones concretas que analicen las causas del conflicto y las solucionen de raíz. Es una transformación necesaria para construir la democracia y mediante esta después de 100 años de soledad y olvido, como lo dijo el maestro García Márquez, estas personas vuelvan a tener otra oportunidad sobre la tierra.

\section{Bibliografía}

Castillo, Raúl; Rafael et al (2012), Arte para la inclusión y la transformación social. Bilbao: Equipo del Observatorio del Tercer Sector de Bizkaia.

Christie, Nils (1984), The limits of pain. Oslo: Universitetsforlaget.

Figueroa, P y Moreno, E (2014), Revista de Arte y Derecho. Reparación Simbólica: procesos artísticos y pedagógicos en escenarios sociales.

PAtiÑo, Andrés (2010), Las reparaciones simbólicas en escenarios de justicia transicional. Revista Latinoamericana de Derechos Humanos Vol. 21 (2): 60.

RocA, José y SuArez, Sylvia (2012), Arte en Colombia 1992-2012. Barcelona: Luwerg y Transpolítico.

Sierra, Yolanda (2014), Relaciones entre el arte y los derechos humanos. Revista Derecho Del Estado n. 32, pp. 77-100.

Rousset, Andrés (2011), El concepto de reparación integral en la jurisprudencia de la Corte Interamericana de Derechos Humanos Revista Internacional de Derechos Humanos, N 5901.

Umaña Eduardo, Falls et al (1962), La Violencia en Colombia. Bogotá: Tercer Mundo.

Uprimny, Rodrigo \& SAFfón, Maria Paula (2009), Reparaciones transformadoras, justicia distributiva y profundización democrática. Reparar en Colombia: los dilemas en contextos de conflicto, pobreza y exclusión. Dejusticia \& ICTJ (pp. 31-71). 
Uprimny, Catalina (2014), Memoria y reparación simbólica: experiencia con algunas iniciativas no oficiales de memoria en Colombia Revista Arte y Derecho n. 11. p. 78.

Verdad Abierta (2012), ¿Verdad a medias, reparación inconclusa? [en línea], disponible en: http:// $w w w . v e r d a d a b i e r t a . c o m / c o m p o n e n t / c o n t e n t / a r t i c l e / 45-r e p a r a c i o n e s-a-v i c t i m a s / 3924-$ mampujan-iverdad-a-medias-reparacion-inconclusa. (Consultada el 24 de septiembre de 2017).

Jurisprudencia y tesis aisladas

Corte Interamericana de Derechos humanos, Casos: Rodrigues Veslasques contra Honduras, González y otras contra México.

Tribunal Superior del Distrito de Bogotá. Col. Sala de justicia y paz, 29 de junio de 2010. CP. ULDI TERESA JIMÉNEZ LÓPEZ. Postulados: Edwar Cobos TÉLlEz y Uber Enrique BANQUÉZ M.

Corte Constitucional, sentencia C-370 del 18 de mayo de 2006, MP Manuel José Cepeda Espinosa.

Legislación

Constitución Política de Colombia de 1991.

Ley 1448 de 2011(ley de víctimas y restitución de tierras)

\section{Informes particulares}

Cifras tomadas del Registro único de víctimas (RUV) Estos datos son tomados desde un punto de vista territorial y expresan las víctimas registradas en todo el territorio nacional. Las cifras concretas por violaciones a derechos humanos son: Desplazamiento, 6.977.713; Desaparición forzada, 164.851; Homicidio, 981.509 entre otros.

Departamento Administrativo Nacional de Estadística (DANE) (2016), Pobreza monetaria y multidimensional en Colombia 2015 [en línea], disponible en: $h t t p s: / / w w w . d a n e$. gov.co/files/investigaciones/condiciones_vida/pobreza/bol_pobreza_15_.pdf (consultado el 24 de septiembre de 2017).

Centro Nacional de Memoria Histórica (2013). Informe: ¡Basta ya! Colombia: Memorias de guerra y dignidad, [en línea], disponible en: http://www.centrodememoriahistorica.gov.co/descargas/informes2013/bastaYa/basta-ya-memorias-guerra-dignidad-new9-agosto.pdf.

Estas cifras son oficiales, fueron tomadas del Registro Único de Víctimas. Institución creada por la ley 1448 de 2011 como una propuesta para el reconocimiento de las víctimas del conflicto armado en el país. Sin embargo es un estimado que se hace con base en diferentes mecanismos de recopilación de datos, que pueden tener insuficiencia en algunos casos por las mismas complejidades del conflicto. 
Centro Nacional de Memoria Histórica (2013), Informe: ¡Basta ya! Colombia: Memorias de guerra y dignidad, [en línea], disponible en: http://www.centrodememoriahistorica.gov.co/descargas/informes2013/bastaYa/basta-ya-memorias-guerra-dignidad-new9-agosto.pdf. p. 16.

Centro Nacional de Memoria Histórica (2012), Mampuján. Crónica de un desplazamiento, [en línea], disponible en: http://www.banrepcultural.org/blaavirtual/memoria-historica/documentales (consultado 24 de septiembre de 2017). 